\title{
On the Categorization of Admired and Disliked Exemplars of Admired and Disliked Racial Groups
}

\author{
Jennifer A. Richeson \\ Northwestern University
}

\author{
Sophie Trawalter \\ Dartmouth College
}

\begin{abstract}
The present work examined the influence of affective fit in the racial categorization process. Study 1 tested whether famous exemplars of stigmatized and nonstigmatized racial groups are categorized by race at differential rates, depending on whether they are admired or disliked. Using an inverted-face paradigm, Study 2 examined whether racial categorization accuracy differs for admired and disliked exemplars of these groups. Study 3 examined the influence of collective self-esteem on Whites' tendency to differentially categorize admired and disliked Black and White exemplars. Last, Study 4 replicated the pattern of results found in the previous studies for White participants, making use of unknown exemplars about whom participants learned either positive or negative information prior to categorizing them. Taken together, the results suggested that phenotypically irrelevant affective information regarding exemplars and their social group memberships influences the racial categorization process. Implications for prejudice and stereotyping are discussed.
\end{abstract}

Keywords: social categorization, automatic evaluation, race, person perception

When Time magazine featured the mug shot taken shortly after O. J. Simpson was arrested for the brutal murders of his wife, Nicole Simpson, and her friend Ron Goldman, an immediate backlash ensued. Apparently, the magazine's editorial staff approved the use of a doctored mug shot in which O. J.'s skin had been darkened, reportedly in order to make him look more tragic and sinister. Civil rights groups were appalled at Time's actions because, in essence, as O. J. Simpson became a criminal defendant, his image was altered in a way that made him more phenotypically Black or African American. That is, the image of O. J. Simpson as a "criminal" or "murderer" somehow needed to be Blacker than O. J. Simpson the adored professional athlete and movie star. This "Blackening" of O. J. Simpson after his arrest may not have occurred solely on the cover of Time, however. Becoming the prime suspect in two brutal murders may have "Blackened" Simpson in the minds of the American public as well. That is, notoriety may have made Simpson seem more "Black" than ever before. The purpose of the present research was to examine this possibility. Specifically, are disliked exemplars of disliked racial groups (e.g., "O. J. the criminal") perceived as members of their groups more

Jennifer A. Richeson, Department of Psychology and Institute for Policy Research, Northwestern University; Sophie Trawalter, Department of Psychological and Brain Sciences, Dartmouth College.

This research was supported by a Rockefeller Center Faculty Fellowship from Dartmouth College. Furthermore, portions of this article were written while Jennifer A. Richeson was a Visiting Fellow at the Research Institute for Comparative Studies in Race and Ethnicity at Stanford University. We thank Natalie Hornak, Caitlin Farrell, Carolyn Parma, Richard Nussbaum, Shermaine Jones, and Kurt Peters for help with data collection, as well as Michael Zárate, Nicole Shelton, Nalini Ambady, Neil Macrae, and Todd Heatherton for comments on previous versions of this article.

Correspondence concerning this article should be addressed to Jennifer A. Richeson, Department of Psychology, Northwestern University, 2029 Sheridan Road, Evanston, IL 60208. E-mail: jriches@ northwestern.edu readily than admired exemplars (e.g., "O. J. the star")? Similarly, are admired exemplars of liked racial groups perceived as members of their group more readily than disliked exemplars?

\section{Admired Versus Disliked Exemplars}

A number of recent studies have demonstrated the amazing influences that atypical exemplars can have on racial attitudes (e.g., Bodenhausen, Schwarz, Bless, \& Wänke, 1995; Richeson \& Ambady, 2003). For instance, brief exposure to admired Black exemplars (e.g., Oprah Winfrey) led to less endorsement of discriminatory statements, compared with exposure to all White exemplars (Bodenhausen et al., 1995, Study 1) or to Black exemplars that are liked less (e.g., Spike Lee; Bodenhausen et al., 1995, Study 2). In an equally compelling series of studies, exposure to admired Black exemplars and disliked White exemplars was found to reduce automatic racial bias for at least $24 \mathrm{hr}$ after exposure (Dasgupta \& Greenwald, 2001). Presumably, individuals used their attitudes about the exemplars as a heuristic to shape their judgments and evaluations of the group as a whole (Bodenhausen et al., 1995). Consequently, evaluations of the group became more positive.

These findings are predicated on the difference between automatically activated attitudes triggered by the particular exemplars and the attitudes typically associated with the relevant groups. That is, Oprah is admired more than Blacks as a group. When thinking of Oprah, consequently, evaluations of Blacks are improved. Dasgupta and Greenwald (2001) asserted that automatic prejudice may even be supported, if not bolstered, by media portrayals in which the race of Black criminals is emphasized, whereas the race of White criminals is ignored. Moreover, they argued that the success of their paradigm in attenuating automatic racial bias stemmed from participants' being forced to "classify admired and disliked individuals by race," and therefore, they were made aware of both "exemplars' racial group membership as well as their valence" (p. 
808). As a result, perceptions of Blacks become less negative and perceptions of Whites become more negative.

The underlying logic of this intervention rests on the assumption that admired and disliked Black and White exemplars are differentially linked to their respective racial groups. That is, participants must be "forced" to categorize disliked Whites and admired Blacks into their racial groups. This is a provocative hypothesis that heretofore has not been tested directly and, therefore, is the focus of the present investigation. That is, the present work sought to address the gap between previous literature examining the effects of atypical exemplars on attitudes and category evaluation and research on category typicality. Specifically, we considered the facility with which individuals can classify admired and disliked individuals by race, as a cue to the differential fit between these exemplars and their racial groups. On the basis of the results of Dasgupta and Greenwald (2001), we expected disliked exemplars of stigmatized groups to be categorized more quickly than admired exemplars, and we expected disliked exemplars of nonstigmatized groups to be categorized more slowly than admired exemplars.

\section{Category Inclusion}

The predictions of the present research are grounded in previous research in cognitive and social psychology, examining exemplarcategory fit. Research examining nonsocial stimuli has shown that certain exemplars "fit" better within their categories than do others (Jolicoeur, Gluck, \& Kosslyn, 1984; Posner \& Keele, 1968; Rosch, 1978). It is a well-known finding, for instance, that a robin is a more typical bird than an ostrich or a penguin (Rosch, Mervis, Gray, Johnson, \& Boyes-Braem, 1976). Robins correspond with our general perceptions of "what birds are like" more than penguins do, and, consequently, they are categorized as birds faster than are penguins (Rips, Shoben, \& Smith, 1973). Building on this work, Rothbart and colleagues proposed a prototype model of social categorization (see Rothbart \& John, 1985). They wrote,

not all logical members of the category are equally represented, and more radically, the criteria for category membership may not be the defining features of a category (e.g., morphology for women, skin color for Blacks) but overall goodness of fit of the individual to the stereotype of the group. (Rothbart \& Lewis, 1988, p. 862)

Thus, inclusion in social categories should also vary as a function of an exemplar's "goodness of fit" with the prototype of the group. Similarly, exemplar theories of social categorization suggest that categorization of new, potential instances of a category stems from the similarity of those instances to particular exemplars of the category that are stored in memory (Smith \& Zárate, 1990, 1992; Zárate \& Smith, 1990). Both prototype and exemplar models suggest, however, that categorization involves the match between the object in need of categorization and a stored "image" (i.e., either a prototype or particular cases). Consistent with these theories, work on subtyping finds that the traits and characteristics of atypical members of social groups rarely generalize to the larger group (Brewer, Dull, \& Lui, 1981; Kunda \& Oleson, 1995; Maurer, Park, \& Rothbart, 1995; Rothbart \& Lewis, 1988; Weber \& Crocker, 1983). Similarly, relative to atypical group members, typical group members are more likely to be primed by their category labels (Rothbart, Sriram, \& Davis-Stitt, 1996).
Although supportive of these goodness-of-fit theories, the majority of this work has used verbal labels to direct categorization. That is, participants are explicitly told to which categories exemplars belong. The treatment of atypical exemplars may differ if photographs or videotapes, rather than verbal labels, are used to cue group membership (Gilbert \& Hixon, 1991; Macrae \& Bodenhausen, 2000). When presented with photographs, for instance, individuals can simply rely on seemingly diagnostic features of the exemplars to assign membership in visible categories (Blair, Judd, Sadler, \& Jenkins, 2002; Livingston \& Brewer, 2002; Maddox \& Gray, 2002; but see also Olson, Lambert, \& Zacks, 2004; Zárate \& Sandoval, 1995). When famous (or infamous) exemplars are used, furthermore, participants do not need to perceive the exemplars' racial group memberships but can simply generate them from memory. Hence, it is not obvious that either group-irrelevant affective information or even information about counterstereotypicality will necessarily impact the facility with which members of visual racial groups will be categorized in paradigms that make use of photographs or other visual displays. In other words, at present there is little evidence indicating that affective information regarding exemplar typicality will impact racial categorization efficiency in paradigms using visual displays. Given the potential implications of the finding that affectively dissimilar exemplars are cognitively distanced from their racial groups, much like ostriches are cognitively distanced from the bird category, it is important to provide a stringent, direct test of the hypothesis.

\section{Function of Attitudes in Social Perception}

The available data relevant to this prediction are equivocal at best. For instance, Fazio $(1995,2001)$ has argued that attitudes serve an orienting function, such that objects for which perceivers have strong or accessible attitudes are differentially attended to, in comparison with objects for which perceivers' attitudes are less accessible (Roskos-Ewoldsen \& Fazio, 1992). For example, attitude-evoking objects were more likely to be noticed after brief exposure, and to interfere with performance on a visual search task, compared with nonevoking objects. According to this view, then, both admired and disliked exemplars should be categorized more quickly than unknown exemplars, but not necessarily any faster than one another. Furthermore, the racial group membership of exemplars would not be expected to moderate the influence of attitude strength on racial categorization.

In contrast to this view, recent research suggests that the valence of one's attitudes may also influence the facility with which the attitude objects are categorized. The affective Simon task provides a clear example of this position (De Houwer, Crombez, Baeyens, \& Hermans, 2001; De Houwer \& Eelen, 1998). In the affective Simon task, participants are required to respond to neutral stimulus items (e.g., nouns and adjectives) using words that connote valence (e.g., positive and negative, respectively). When a noun such as heaven appears on the screen, for instance, participants are expected to say positive and can typically do so quite easily. When a noun such as devil appears, on the other hand, participants have a harder time saying positive in order to indicate that devil is a noun. Thus, automatically activated attitudes regarding devil inhibit its categorization as a noun, because noun is procedurally linked to positive. That is, devil is harder to associate with positive than is heaven. 
Some evidence in support of this hypothesis can also be gleaned from research using a task similar to the affective Simon task, namely, the Implicit Association Test (IAT; see Greenwald, McGhee, \& Schwartz, 1998). Like the Simon task, the IAT requires participants to associate racial categories, such as Whites and Blacks, with positive and negative concepts. Recent research finds that White participants find it easier to associate admired White exemplars with positive concepts, compared with disliked White exemplars, and they find it easier to associate disliked Black exemplars with negative concepts, compared with admired Black exemplars (Govan \& Williams, 2004; Mitchell, Nosek, \& Banaji, 2003). Specifically, IAT paradigms in which the names of disliked White and admired Black exemplars are used yield less pro-White attitude bias, compared with the typical paradigm in which the names of unfamiliar White and Black exemplars are used (Govan \& Williams, 2004).

Similar to Dasgupta and Greenwald (2001), an underlying, but often unstated, presumption of these findings is that admired Black and disliked White exemplars are affectively dissimilar from their respective racial categories. That is, in the language of prototype theory, there is greater psychological distance between admired Black and disliked White exemplars and the prototype of their respective racial categories. Consequently, although they facilitate associations between Black and positive and White and negative, affectively atypical exemplars should be verified as group members more slowly than disliked Black and admired White exemplars. In other words, disliked exemplars may be harder to associate with a positively evaluated racial group (i.e., Whites) than are admired exemplars, but they may be easier to associate with a negatively evaluated racial group (i.e., Blacks) than are admired exemplars.

The purpose of the present work is to test this possibility. Specifically, we measured the speed with which photographs of admired and disliked exemplars of positively valenced and negatively valenced racial groups are categorized into their relative racial groups. Unlike in the aforementioned previous work, however, the studies reported herein did not explicitly activate valence nor require participants to make any valence judgments. Consequently, the present research examined the automatic activation of affect regarding exemplars and their racial groups, and, furthermore, whether affective fit influences racial categorization. Consistent with prototype theory, we predicted that exemplars who are affectively consistent with the evaluation of their racial group would be categorized more quickly than affectively inconsistent exemplars.

\section{Overview of Studies}

The primary purpose of the present work, therefore, was to extend previous research on categorization by examining the differential category inclusion of admired and disliked members of visible racial categories. Specifically, we investigated the inclusion of admired and disliked exemplars of the racial categories BlackAfrican American and White-Caucasian. To measure category inclusion, we used a category-naming paradigm in which the latencies to categorize admired and disliked exemplars correctly were assessed. Similar to recent studies examining the influence of admired and disliked exemplars on attitudes (e.g., Dasgupta \& Greenwald, 2001), the targets in Studies 1 through 3 of the present work were famous (i.e., highly familiar) individuals. Specifically, Studies 1 and 3 examined whether White participants categorize admired Black and disliked White exemplars more slowly than disliked Black and admired White exemplars, as well as individual differences that may moderate the tendency to do so. Study 2 examined whether White perceivers' categorization judgments, in addition to latencies, are influenced by exemplar valence. Last, Study 4 examined whether positive and negative unfamiliar Black and White exemplars are also categorized at differential rates, by both White and Black perceivers. Taken together, these studies demonstrate the influence of exemplar-category affective fit on the racial categorization process.

\section{Study 1}

Study 1 directly investigated the differential inclusion of admired and disliked exemplars of liked and disliked racial categories (i.e., Black and White from the perspective of White Americans). To measure category inclusion, we used a category-naming, response latency paradigm. Similar to recent studies examining the influence of admired and disliked exemplars on attitudes (e.g., Dasgupta \& Greenwald, 2001), the targets in the present work were famous (i.e., highly familiar) individuals. Famous exemplars are useful in such a paradigm because there is no need either to articulate to participants the racial group memberships of the targets or to introduce new attitudes about them, reducing demand characteristics. Because they are relatively atypical of their racial groups, we predicted that disliked White exemplars and admired Black exemplars would be categorized more slowly than admired White exemplars and disliked Black exemplars.

\section{Method}

\section{Stimulus Acquisition and Pretesting}

We generated a list of 28 famous Black and White male exemplars, drawn primarily from previous studies examining the effects of admired and disliked exemplars on category evaluation (e.g., Dasgupta \& Greenwald, 2001), as well as from current events. Fourteen of the exemplars were Black, and 14 were White. Further, 14 exemplars were thought to be generally admired, and 14 were thought to be generally disliked ${ }^{1}$ (see the Appendix). Then, we obtained a photograph of each exemplar in which the exemplar was displaying a neutral facial expression and facing the camera. Each photograph was cropped to uniform size in which only the head and torso were in view, placed in a neutral background, and then converted to gray scale. In order to ensure that the exemplars were liked or disliked, as well as familiar to our participants, we had each exemplar rated on both dimensions by 16 White undergraduate raters ( 8 men and 8 women) on 9-point scales $(1=$ not at all, $9=$ extremely $)$. If the target was unfamiliar, raters were instructed to make a note, skip the ratings, and move on to the next exemplar. Given its relevance to categorization efficiency, we also obtained ratings on how stereotypical of their racial group each exemplar was perceived to be.

\footnotetext{
${ }^{1}$ The famous (and infamous) exemplars adopted for use in Studies 1 through 3 were selected, and the data for these studies were collected, several years prior to the publication of this article (circa Congressperson Gary Condit's infamy). Perceptions of individual exemplars may have changed since the data were collected for these studies (e.g., Barry Bonds, Eminem).
} 
Familiarity (fame). No exemplar was skipped more than once, and, therefore, all were considered in the present analyses. We averaged ratings of familiarity for the admired and disliked White and Black exemplars, then conducted a 2 (exemplar valence) $\times 2$ (exemplar race) analysis of variance (ANOVA). Analyses revealed no differences in the fame of Black compared with White exemplars $(M \mathrm{~s}=7.9$ and 8.1$)$, or between admired compared with disliked exemplars $(M \mathrm{~s}=8.0$ and 8.0, $p \mathrm{~s}>.2)$. Hence, it is unlikely that differential familiarity could account for any differences that emerge in categorization latencies.

Likeability. The mean ratings for likeability were subjected to the same $2 \times 2$ ANOVA as the fame ratings, and as anticipated, disliked exemplars were liked less than admired exemplars (respective $M \mathrm{~s}=3.2$ and 7.0), $t(15)=10.9, p<.0001$. Similarly, admired Black exemplars were rated as more likable than disliked Black exemplars, $t(15)=6.08, p<.0001$, and admired White exemplars were rated as more likable than disliked White exemplars, $t(15)=15.06, p<.0001$. Of interest, admired Black and admired White exemplars were equally likable (respective $M \mathrm{~s}=6.9$ and 7.0), $t(15)=0.33, n s$, whereas disliked White exemplars were liked less than disliked Black exemplars (respective $M \mathrm{~s}=3.7$ and 5.7), $t(15)=4.64$, $p<.001$.

Stereotypicality. The ANOVA of stereotypicality ratings yielded a significant main effect of exemplar race, $F(1,15)=14.03, p<.005$, and the effect of exemplar valence approached conventional levels of statistical significance, $F(1,15)=4.01, p<.06$. Each of these effects was moderated by the interaction between race and valence, $F(1,15)=12.62, p<.01$. Simple effects tests revealed that admired White exemplars were rated as more stereotypical of Whites as a group $(M=5.8)$ than disliked White exemplars $(M=3.7), t(15)=4.4, p<.001$. Conversely, disliked Black exemplars were rated as relatively more stereotypical of Blacks as a group $(M=6.4)$ than admired Black exemplars $(M=5.0), t(15)=2.5, p<.05$.

Overall, these results suggest that admired Whites and disliked Blacks are perceived as being more stereotypical of their racial groups than disliked Whites and admired Blacks. In other words, perceptions of stereotypicality seem to be yoked to positive and negative evaluations, at least for the Black and White racial groups. Perhaps because Whites constitute a dominant racial group and Blacks represent a stigmatized racial group in the United States, disliked White exemplars and admired Black exemplars are perceived as less stereotypical of their respective racial groups than admired Whites and disliked Blacks. Nevertheless, according to the prototype theory of categorization, atypical exemplars (either by virtue of their associated affect or their rated stereotypicality) should be categorized at slower rates than typical exemplars. If, however, individuals use phenotypic information to categorize the exemplars, then exemplar typicality should not influence the rate of categorization. Because we felt it important in our initial investigation of the effects of affectively atypical exemplars on categorization to include famous admired and disliked exemplars similar to those used in the previous studies examining the effects of such exemplars on category evaluation (e.g., Bodenhausen et al., 1995; Govan $\&$ Williams, 2004), we used the 28 exemplars examined in pretesting to investigate the veracity of these competing hypotheses.

\section{Main Study}

Participants and design. Twenty-one White undergraduates participated in the experiment for partial course credit. The experiment was a 2 (exemplar type: admired or disliked) $\times 2$ (exemplar race: White or Black) repeated measures design. ${ }^{2}$

Procedure. The experiment consisted of three phases: (a) training, (b) documentation of familiarity, and (c) categorization. In Phase 1, the name of each exemplar was presented for $3 \mathrm{~s}$, followed by the appropriate photograph $(2 \mathrm{~s})$; then the name was presented again $(2 \mathrm{~s})$ in order to reinforce the encoding of face and name. Two filler exemplars (Bill Clinton and George Bush) were presented first as practice trials; then the sequence was repeated for each of the target exemplars in random order. After Phase 1 , participants' ability to recognize each exemplar by photograph was tested in Phase 2. Specifically, participants were shown the photograph of each exemplar for up to $5 \mathrm{~s}$, during which they were asked to write down that exemplar's name on a sheet of paper. Participants' responses were examined to ensure that they could recognize each of the exemplars by photograph.

Finally, Phase 3 consisted of the categorization task in which participants indicated the racial group membership (White or Black) of each of the exemplars from Phases 1 and 2, as well as 14 unknown individuals (7 of each race), as quickly and accurately as possible. Participants were instructed to fixate on a small black cross in the center of the screen where each photograph appeared, one at a time, and remained until participants indicated, by means of a key press, the person's race. The intertrial interval was $1,000 \mathrm{~ms}$. After 2 practice trials, participants completed two blocks of 42 (28 famous and 14 unfamiliar exemplars) randomized trials, for a total of 84 experimental trials. Upon completion, participants were debriefed, thanked, and dismissed.

\section{Results and Discussion}

Category-naming times slower than three standard deviations from the mean (those greater than $1,100 \mathrm{~ms}$ ) were recoded as 1,100 ms (see Ratcliff, 1993), and trials in which participants categorized the exemplars incorrectly were excluded from analyses $(1.4 \%$ of observations). Next, a log transformation was performed on the remaining data, which were then submitted to a 2 (exemplar type: admired or disliked) $\times 2$ (exemplar race: Black or White) repeated measures ANOVA. ${ }^{3}$ Consistent with predictions, the interaction between exemplar race and exemplar type was reliable, $F(1,20)=$ 9.81, $p<.01$. As shown in Figure 1, participants took longer to indicate the race of admired Blacks (e.g., Martin Luther King Jr.) than disliked Blacks (e.g., O. J.), $t(20)=2.15, p<.05$. Conversely, participants categorized admired Whites (e.g., John F Kennedy) faster than disliked Whites (e.g., Timothy McVeigh), $t(20)=2.08, p=.05$. These results suggest that admired Whites are included in the racial category White more readily than disliked Whites, but admired Blacks are included in the racial category Black less readily than disliked Blacks.

In addition to category inclusion, Study 1 also examined the influence of exemplar type on the marked categorization advantage - the tendency for members of nonnormative racial and gender categories to be categorized more quickly than White males (Fiske, 1998; Zárate \& Smith, 1990). For instance, Black males are categorized by race more quickly than White males (Stroessner, 1996). One constraint on the marked categorization advantage has been identified, however. Zárate and Sandoval (1995) found that the categorization advantage of female targets was attenuated if they held a counterstereotypical occupation. In other words, females were categorized by gender more quickly than males, unless they were portrayed as gender atypical.

On the basis of this work, one would expect that admired Black exemplars would attenuate the marked categorization advantage because they are categorized by race more slowly than are disliked Black exemplars. In order to examine this possibility, we tested the reliability of the effect of exemplar race for both disliked and admired exemplars. Consistent with the marked categorization

\footnotetext{
${ }^{2}$ Unfortunately, participant sex information was not recorded in this study.

${ }^{3}$ The mean reaction time values in the figures and main text have been retransformed into millisecond units.
} 


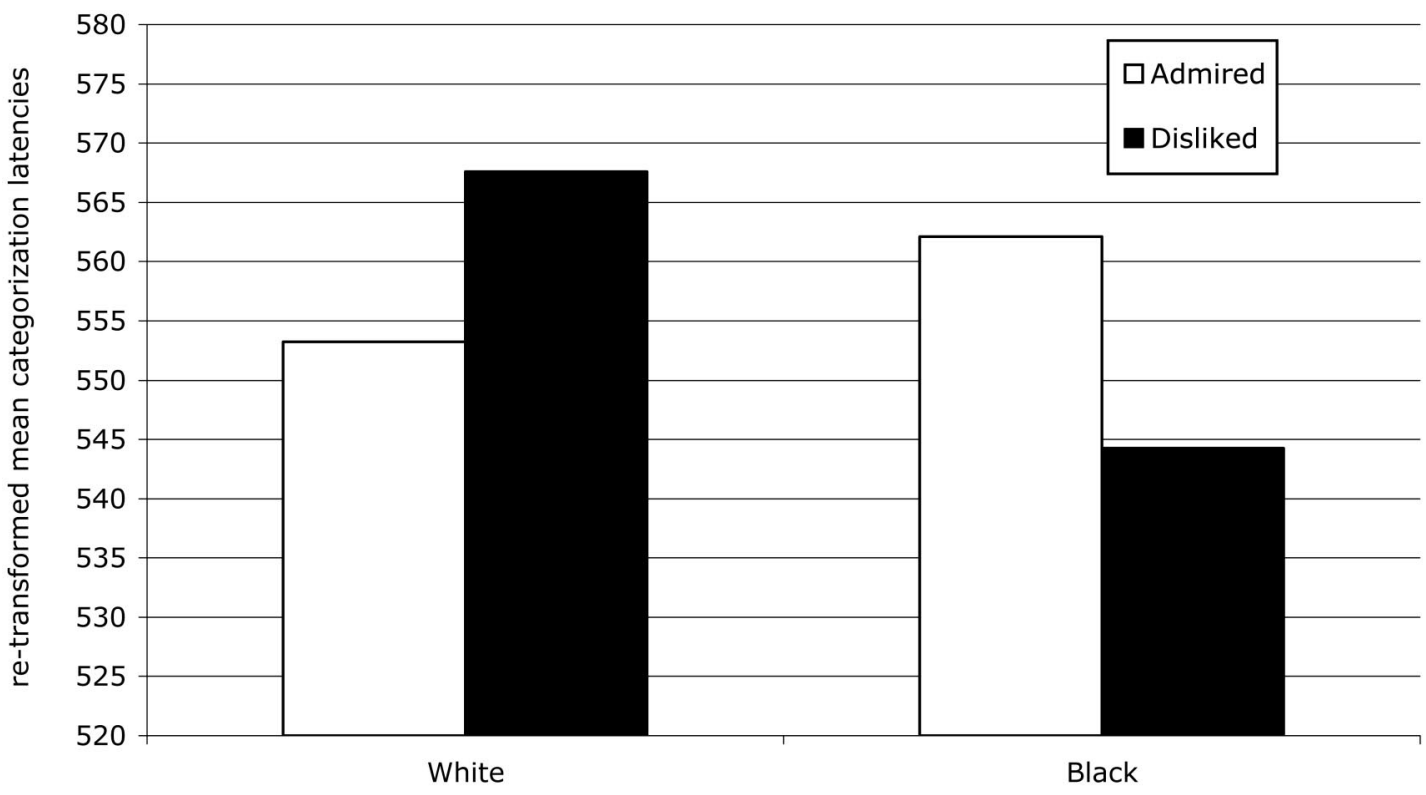

Figure 1. Study 1: Racial categorization latency for admired and disliked exemplars.

advantage, disliked Black exemplars were categorized more quickly than disliked White exemplars, $t(20)=2.60, p<.02$. By contrast, admired Black exemplars were not categorized any faster than admired White exemplars, $t(20) 0.91, p>.30 .^{4}$ These results suggest that the marked categorization advantage may also be vulnerable to fluctuations in the affective information associated with the exemplars. Taken together, the present results suggest that even highly familiar atypical exemplars of visible racial categories may be perceived as relatively poor exemplars of their racial groups.

\section{Study 2}

Study 1 revealed differential categorization latencies for admired and disliked Black and White exemplars. The primary purpose of Study 2 was to examine whether the accuracy of categorization judgments may also be influenced by the affect associated with the exemplar. In Study 1, the commission of errors was too infrequent to investigate this hypothesis adequately. Thus, the present study drew upon research in face perception demonstrating that inverting faces dramatically increases the difficulty individuals have in processing them (Leder \& Bruce, 2000; Valentine, 1988; Yin, 1969). This work suggests that face inversion slows, but does not completely disrupt, the identification of individual faces. The findings of Study 1 suggest that participants do use identity information about the exemplars to guide categorization, despite the lack of necessity to do so. Consequently, inverting the photographs of our disliked and admired Black and White exemplars should increase the number of categorization errors, thereby allowing for a reliable assessment of any patterns in the error rates. Consistent with the findings of Study 1, we expected that admired Black and disliked White exemplars would be categorized less accurately than disliked Black and admired White exemplars.

\section{Method}

\section{Participants and Design}

Sixteen White undergraduates ( 7 women) participated in the experiment for partial course credit. The experiment was a 2 (exemplar type: admired or disliked) $\times 2$ (exemplar race: White or Black) repeated measures design.

\section{Procedure}

The procedures were identical to those described in Study 1 with one slight addendum. In Phase 3, the racial categorization phase, the photographs were presented upside down.

\section{Results and Discussion}

\section{Categorization Accuracy}

Initial analyses revealed that the overall error rate was greater than $5 \%$. For each participant, trials in which the participant judged target race incorrectly were coded as 1 , and correct trials were coded as 0 . Next, the error rates for each participant, for each trial type and target race, were calculated by averaging the codes reflecting correct or incorrect judgments. Participants' error rates were then subjected to a 2 (exemplar type: admired or disliked) $\times$

\footnotetext{
${ }^{4}$ We did not include the unfamiliar targets in our primary analyses given that participants were only presented with these targets during Phase 3 rather than all three phases of the experiment, and, consequently, target fame was confounded with the extent of participants' recent exposure to the targets-a variable that is known to influence reaction times. Hence, we thought it inappropriate to include them in the main set of analyses. We did, however, examine whether the marked categorization advantage was observed in the unfamiliar targets. Consistent with previous research, Black targets were categorized faster than White targets, $t(20)=4.50, p<$ .0002 .
} 


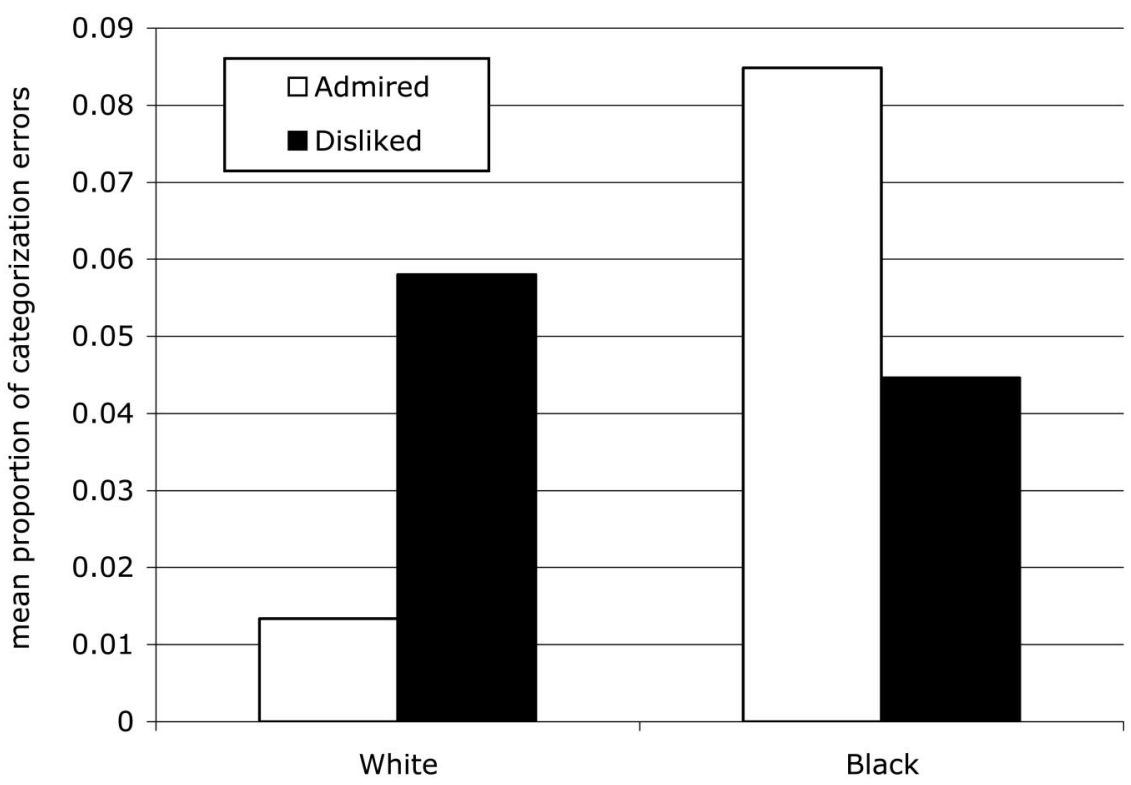

Figure 2. Study 2: Racial miscategorization by exemplar race and likeability.

2 (exemplar race: Black or White) repeated measures ANOVA. Results revealed a main effect of exemplar race, $F(1,15)=7.06$, $p<.05$. Black exemplars were categorized incorrectly more often than White exemplars. Furthermore, the expected interaction between exemplar race and exemplar type was also reliable, $F(1$, $15)=15.08, p<.002$. As shown in Figure 2, participants miscategorized admired Blacks (e.g., Martin Luther King Jr.) more often than disliked Blacks (e.g., O. J.), $t(15)=1.86, p<.05$, but they miscategorized admired Whites (e.g., John F. Kennedy) less often than disliked Whites (e.g., Timothy McVeigh), $t(15)=2.82$, $p<.05$. These results are consistent with Study 1, suggesting the influence of affective orientations toward particular exemplars on the racial categorization process.

\section{Categorization Latencies}

Similar to the analyses reported in Study 1, we also examined the latencies associated with participants' categorization judgments, but only for correctly categorized exemplars (Fazio, 1990). Specifically, category-naming times slower than 3 standard deviations from the mean (greater than 1,200 ms) were recoded as 1,200 ms (see Ratcliff, 1993). Then a log transformation was performed, and the data were submitted to a 2 (exemplar type: admired or disliked) $\times 2$ (exemplar race: Black or White) repeated measures ANOVA. Consistent with predictions, the interaction between exemplar race and exemplar type was reliable, $F(1,15)=$ $10.18, p<.01$. Simple effects tests revealed that participants took longer to indicate the race of admired Blacks $(M=633 \mathrm{~ms})$ than disliked Blacks $(M=611 \mathrm{~ms}), t(15)=2.83, p<.05$. Unlike in Study 1, however, participants did not categorize admired Whites $(M=633)$ faster than disliked Whites $(M=623 \mathrm{~ms}), t(15)=0.63, n s$.

Similar to Study 1, we again examined the influence of exemplar type on the marked categorization advantage. Consistent with the marked categorization advantage, disliked Black exemplars were categorized more quickly than disliked White exemplars, $t(15)=2.30, p<.05$. By contrast, admired Black exemplars were not categorized any faster than admired White exemplars, $t(15)=$ $0.63, n s .5$

Taken together, the results of Studies 1 and 2 are compelling when considered in light of the fact that participants were categorizing photographs of exemplars that are well-known. Both the visual display and the identity of each exemplar were sufficient to categorize them quickly and accurately. Nevertheless, differences in categorization latency and accuracy emerged as a function of whether the exemplar is admired or disliked. It is not clear at present why the effect of differential categorization latencies emerged for the Black exemplars but not the White exemplars. One possibility is that the face inversion paradigm led participants to adopt different speed-accuracy trade-off criteria for Black compared with White faces. Indeed, recall that participants categorized the White exemplars more accurately than the Black exemplars. In other words, they may have slowed their responses to the White exemplars in the service of accuracy to a greater extent than to the Black exemplars. Of interest, however, the pattern of accuracy data suggests that participants were sensitive to whether the White exemplars were admired or disliked, despite their failure to reveal a statistically significant difference in their response latencies.

One possible contributor to the pattern of findings observed in Studies 1 and 2 is in-group favoritism. According to social identity theory (Tajfel \& Turner, 1986), individuals tend to perceive their in-groups as being positive and distinct and are motivated to maintain that status. The relatively quick inclusion of admired in-group (White) and disliked out-group (Black) exemplars into their respective racial categories on the part of White perceivers

\footnotetext{
${ }^{5}$ Similar to previous research and Study 1, the marked categorization advantage was also revealed in categorization latencies associated with the unfamiliar targets in Study 2. Unfamiliar Black targets were categorized faster than were unfamiliar White targets, $t(15)=4.32, p<.001$.
} 
may reflect, in part, these perceivers' belief in and/or maintenance of their racial group's positive distinctiveness. If this is indeed the case, then the pattern of categorization observed in Studies 1 and 2 should be moderated by the extent to which participants derive self-esteem from their racial group membership - that is, participants' level of collective self-esteem. The primary aim of Study 3 was to examine this question.

\section{Study 3}

According to social identity theory (Tajfel \& Turner, 1986), individuals are motivated to maintain the positive distinctiveness of groups to which they belong. Perceiving disliked White exemplars and admired Black exemplars as relatively distant nonprototypical exemplars of their respective racial groups would serve to maintain, and perhaps bolster, the positive distinctiveness of the White racial category. Indeed, previous research finds that distancing oneself from unfavorable in-group members (also known as the "black sheep effect") is an effective method of protecting in-group positivity (Marques, Robalo, \& Rocha, 1992; Marques \& Yzerbyt, 1988). Of interest, individuals who are more committed to their groups are especially likely to demonstrate the "black sheep effect" (Marques et al., 1992), as well as to engage in more out-group derogation (Doosje \& Ellemers, 1997). On the basis of this research, we reasoned that White individuals who are particularly invested in their racial group membership might be relatively more likely to reveal the "in-group favoring" pattern of results that emerged in Study 1. In other words, we predicted that the extent to which disliked White exemplars and admired Black exemplars are psychologically distanced ${ }^{6}$ from their group-as evidenced from their differential categorization latencies-should vary as a function of race-based collective self-esteem. Relative to low-esteem individuals, high-esteem individuals were expected to be particularly slow to categorize disliked in-group members (Whites) and admired out-group members (Blacks).

\section{Method}

Thirty-two White undergraduates (21 female) participated in this experiment in exchange for partial course credit. Participants were recruited from among those who had participated in a mass pretesting session at the beginning of the term that included Luhtanen and Crocker's (1992) racespecific Collective Self-Esteem Scale (r-CSES). The r-CSES is a 16-item measure, composed of four subscales that tap feelings regarding one's racial-ethnic group. Because it assesses how positively individuals perceive their group, the Private Collective Self-Esteem (PCSE) subscale was expected to moderate the pattern of racial categorization revealed in Studies 1 and 2. Items include "I feel good about the race/ethnicity I belong to." Previous research shows, however, that how important a group membership is to one's identity also impacts the categorization of ambiguous faces into ethnic categories (e.g., Castano, Yzerbyt, Bourguignon, \& Seron, 2002). Hence, we also examined whether scores on the Importance to Identity subscale may moderate the pattern of results found in studies 1 and 2. Items on the Importance to Identity subscale include "The racial/ethnic group I belong to is an important reflection of who I am." Participants responded to each item using a 7-point Likert-type scale. After appropriate items were reverse scored, the mean of the 4 items associated with each of the two subscales of interest was computed in order to ascertain participants' level of PCSE $(\alpha=.76)$ and identity importance of collective self-esteem (ICSE, $\alpha=.75$ ).
No less than 2 weeks after pretesting, participants were recruited to come into the lab for a study examining "person construal." The procedures were identical to those described for Study 1.

\section{Results and Discussion}

Data were trimmed and transformed in a manner similar to that described for Study 1. Less than $1 \%$ of the trials were errors. Mean log latencies were examined using a mixed model regression procedure in which PCSE (centered), exemplar type (admired or disliked), exemplar race (Black or White), and their interactions were entered as predictors. Results revealed a main effect of race, $F(1,30)=4.08, p=.05$. Consistent with the marked categorization advantage hypothesis, Black exemplars $(M=537 \mathrm{~ms}, S D=$ 89.3) were categorized more quickly than White exemplars $(M=$ $554 \mathrm{~ms}, S D=66.7)$. Furthermore, the now familiar two-way interaction between exemplar race and type was also reliable, $F(1$, $30)=9.99, p<.005$. In replication of Study 1 , on average, admired White exemplars $(M=546 \mathrm{~ms}, S D=66.8)$ were categorized faster than disliked White exemplars $(M=560 \mathrm{~ms}, S D=$ $71.4)$, and disliked Black exemplars $(M=530 \mathrm{~ms}, S D=89.2)$ were categorized faster than admired Black exemplars $(M=545$ $\mathrm{ms}, S D=95.1)$. Consistent with predictions, however, the threeway interaction between PCSE, exemplar race, and exemplar type approached conventional levels of statistical significance, $F(1$, $30)=2.75, p=.10$. We used the unstandardized beta weights from the regression equation in order to map out the three-way interaction pattern plotted in Figure 3. The predicted values for each level of exemplar race and exemplar type for participants with PCSE scores one standard deviation above and below the mean and for participants at the mean are shown in Figure 3 (higher, lower, and moderate PCSE levels, respectively).

Recall that we predicted that participants with higher levels of PCSE would reveal the differential categorization pattern found previously to a greater extent than participants with lower levels of PCSE. Of interest, results revealed that the race by exemplar type interaction was reliable for both participants with higher levels of PCSE, $F(1,30)=6.77, p=.01$, and for participants with lower levels of PCSE, $F(1,30)=12.17, p<.002$, as well as, of course, for participants with moderate levels of PCSE, $F(1,30)=9.99$, $p<.005$. As can be gleaned from Figure 3, however, participants with higher levels of PCSE and moderate levels of PCSE conformed to the predicted pattern of means to a greater extent than participants with lower levels of PCSE.

Supplemental analyses also revealed that the effects of PCSE were exclusive to the Black target exemplars. That is, categorization of the admired and disliked Black exemplars differed as a function of PCSE, interaction $F(1,30)=4.84, p<.05$, but not the categorization of White exemplars, $F(1,30)=0.16, n s$. Specifically, whereas participants at all levels of PCSE tended to categorize disliked White exemplars relatively more slowly than admired White exemplars, $F(1,30)=3.22, p=.08 ; F(1,30)=5.88, p<$ .05 ; and $F(1,30)=5.36, p<.05$, for higher, moderate, and lower PCSE values respectively, only participants with higher and moderate PCSE values categorized disliked Black exemplars faster

\footnotetext{
${ }^{6}$ Our use of the phrase psychologically distanced is not meant to imply that the processes under examination in the present work are intentional, conscious, or the result of motivated processes.
} 


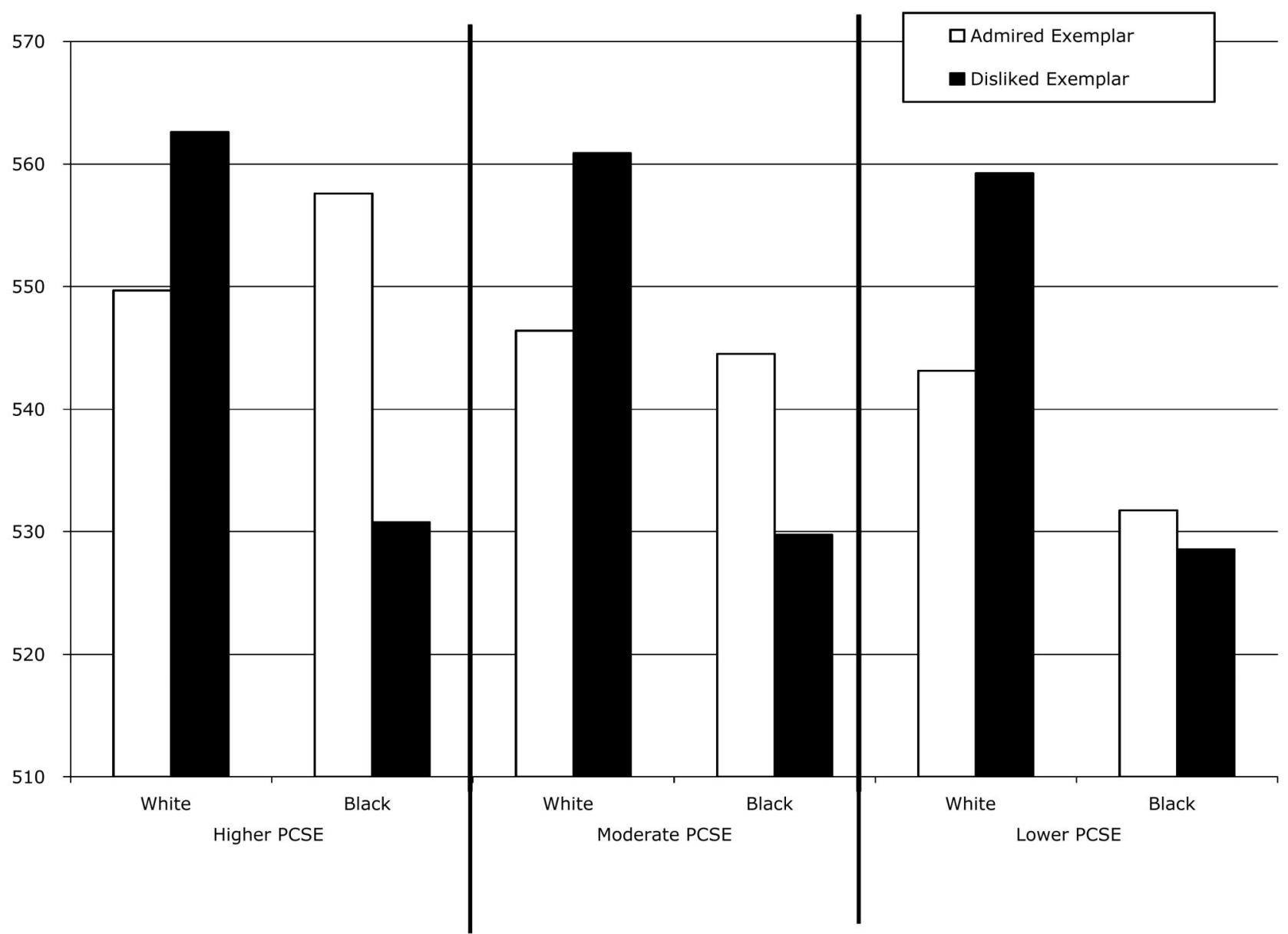

Figure 3. Study 3: Influence of private collective self-esteem (PCSE) on racial categorization latency.

than admired Black exemplars, $F(1,30)=7.65, p<.01 ; F(1$, $30)=3.46, p=.07$; and $F(1,30)=.11, n s$, respectively. Analysis of the correlations between PCSE and categorization latency for each exemplar type also suggested that the effect of PCSE was exclusive to the admired Black exemplars. Specifically, there was a modest, positive correlation between categorization latency and PCSE for the admired Black exemplars, $r(30)=.23, p=.20$, whereas there was little evidence that PCSE predicts categorization latency for the other target types $(r \mathrm{~s}=.02, .08$, and .04 for disliked Black, admired White, and disliked White exemplars, respectively). In other words, participants with lower levels of PCSE did not tend to categorize the admired Black exemplars relatively sluggishly - a response pattern that differs from that found for admired, compared with disliked, Black exemplars in the previous two studies. As a set, these data suggest that positive regard toward one's racial group influences the categorization of admired out-group exemplars, but not necessarily the categorization of either admired or disliked in-group exemplars.

A second set of analyses using the Identity Importance Collective Self-Esteem subscale revealed no reliable effects of identity importance, three-way interaction $F(1,30)=.01, p>$.9. These results could be attributable to the relatively low levels of identity importance reported by our sample $(M=3.0 ; 75 \%$ of scores were less than 3.5 on the 7-point scale). Or, rather, they could suggest that positive affect regarding one's group, rather than identity importance, is critical to the categorization processes under examination in the present work. Future research should examine further the respective roles of these two sources of group esteem, especially given the low levels of identity importance observed herein. Nevertheless, considered in tandem with Studies 1 and 2, the present results suggest that the categorization of unambiguous exemplars of visible social categories may be influenced not only by relevant, seemingly diagnostic physical features of the stimuli, but perhaps also by the congruence or fit between the affective typicality of those targets and the relevant group memberships. ${ }^{7}$

\footnotetext{
${ }^{7}$ Neither the Membership subscale of the r-CSES, which assesses how good a member of the group individuals perceive themselves to be, nor the Public subscale, which assesses how positively individuals believe the group is evaluated by members of other groups, moderated racial categorization. Unlike the Private and Identity subscales, these aspects of collective self-esteem have not been found to moderate patterns of racial categorization or of in-group favoritism in previous research (e.g., Castano et al., 2002; Marques et al., 1992), presumably because it is the extent to which one feels positively about one's group, or is committed to one's group, that shapes such processes.
} 


\section{Study 4}

The results of Studies 1 through 3 provided compelling evidence for the influence of exemplar likeability, and attitudes about the racial categories themselves, on the racial categorization process for White perceivers. Although the findings are striking, they are limited in that the studies included only White participants. Furthermore, the findings of Study 3, in particular, suggested that attitudes toward one's racial group (i.e., positive regard) influence the racial categorization process. By extension, individuals' racial group memberships should influence this process as well. That is, Black and White individuals may reveal different patterns in the latencies with which they categorize admired and disliked White and Black exemplars.

Specific predictions regarding the pattern that Black participants would reveal are not obvious, however. One possibility is that Black participants would reveal the same pattern as White participants. Research using implicit or automatic attitude measures showed that Black individuals often reveal a pro-White attitude bias, similar in direction (but not usually in magnitude) to that observed for Whites (Nosek, Banaji, \& Greenwald, 2002). On the other hand, Black individuals have been found to have high levels of PCSE (e.g., Crocker, Luhtanen, Blaine, \& Broadnax, 1994; Richeson \& Ambady, 2001). On the basis of this work, Black individuals might be expected to be slow to categorize negative in-group exemplars and positive out-group exemplars, compared with the rate at which they categorize positive in-group and negative out-group exemplars. In other words, they might reveal the mirror image of the pattern observed for White participants (see the results of Study 1). The findings and logic of Study 3 would also predict such a pattern of results. Given these competing predictions, one aim of the present experiment was simply to investigate what Black participants actually do and to compare it to the pattern of categorization latencies revealed by White participants.

Furthermore, given the provocative implications of the present work, it is important to reiterate the fact that exemplar stereotypicality and valence (whether they were admired or disliked) were correlated in the previous three studies. Although such correlations may exist in perceptions of many actual famous exemplars of these two races, the individual contributions of exemplar stereotypicality and liking (or admiration) could not be examined. As mentioned previously, we felt it important in our initial investigation of the effects of affectively atypical exemplars on categorization to use exemplars similar to those found in previous studies (e.g., Bodenhausen et al., 1995; Govan \& Williams, 2004; Mitchell et al., 2003); however, it is also important to examine the contribution of exemplar valence when stereotypicality is held constant. That is, can affective orientations toward White and Black exemplars generate different categorization latencies, even when the stereotypicality of the exemplars is controlled? To our knowledge, this question has not been addressed in previous studies examining either categorization or category evaluation.

Moreover, although the use of actual exemplars makes the findings of the present studies more ecologically valid, and, perhaps, particularly important, their use allows for the possibility that differences in the perceptions of the individual exemplars may be influencing the findings. For instance, several of the extremely disliked White exemplars were serial killers, unlike the majority of the disliked Black exemplars. In addition to the decoupling of exemplar stereotypicality and valence, is important to equate the information that perceivers have about the exemplars. In order to address this and the aforementioned issues, we conducted Study 4 in which White and Black participants were provided with information about several White and Black exemplars, whom they subsequently categorized by race. Specifically, participants first viewed pictures of a set of individuals who they were told grew up to become ministers. In order to manipulate the affective orientation toward the exemplars, participants were told that half of the individuals became ministers who were particularly charitable to the poor (thus inducing a positive attitude) and that the other half became ministers who were found to have embezzled or misused monies from the offering (thus inducing a negative attitude; see Castelli, Zogmaister, Smith, \& Arcuri, 2004).

Participants were introduced to individuals who made up each ministerial type, one at a time, and were asked to form an impression of each person. After viewing each exemplar, participants completed a racial categorization task similar to that described in the previous studies. On the basis of the findings of Studies 1 through 3, we predicted that White participants would categorize positive Black exemplars (charitable ministers) more slowly than negative Black exemplars (thieving ministers) and categorize positive White exemplars more quickly than negative White exemplars. We expected Black participants to reveal the opposite pattern: categorize positive Black exemplars more quickly than negative Black exemplars and categorize positive White exemplars more slowly than negative White exemplars.

\section{Method}

\section{Pretesting}

Recall that the primary purpose of Study 4 was to unconfound exemplar valence and stereotypicality in order to understand better the results of Studies 1 through 3. To that end, we asked 15 White undergraduate students to rate how stereotypically White and stereotypically Black several types of individuals were. Of primary concern for the present study were their ratings of how stereotypical of Whites and Blacks were ministers in general, ministers involved in numerous charitable works, and ministers who misspent donated monies. These ratings were each made on a unipolar scale, ranging from 1 (not at all stereotypical) to 7 (very stereotypical). Participants also rated how positive each type of person was on a bipolar scale, ranging from 1 (very negative) to 7 (very positive). Analyses of these ratings revealed that ministers in general were rated as equally stereotypical of Whites and Blacks ( $M \mathrm{~s}=3.5$ and 3.6), $t(14)=$ $0.32, n s$, as were ministers who steal from the donated money $(M \mathrm{~s}=3.5$ and 4.2$), t(14)=1.24, p>.20$, and ministers who are particularly charitable $(M \mathrm{~s}=3.8$ and 4.1$), t(14)=0.72, p>.40$. Of greater pertinence to the purpose of the present investigation, ministers who steal and charitable ministers were rated as being equally stereotypical of Blacks, $t(14)=$ $0.17, p>.8$, and of Whites, $t(14)=-0.79, p>.4$. In addition, as expected, charitable ministers were perceived as more positive than thieving ministers $(M \mathrm{~s}=5.5$ and 2.2), $t(14)=3.27, p<.0005$.

Taken together, these data reveal that the aforementioned information regarding ministers does not affect perceptions of how stereotypical of Blacks and Whites the exemplars are, but it does influence perceptions of positivity. Consequently, using such information in order to shape how likable Black and White exemplars are perceived to be should influence the facility with which those exemplars are subsequently categorized by race. On the basis of the findings of Studies 1 through 3, we expected White perceivers to be slower to categorize liked Black exemplars than disliked 


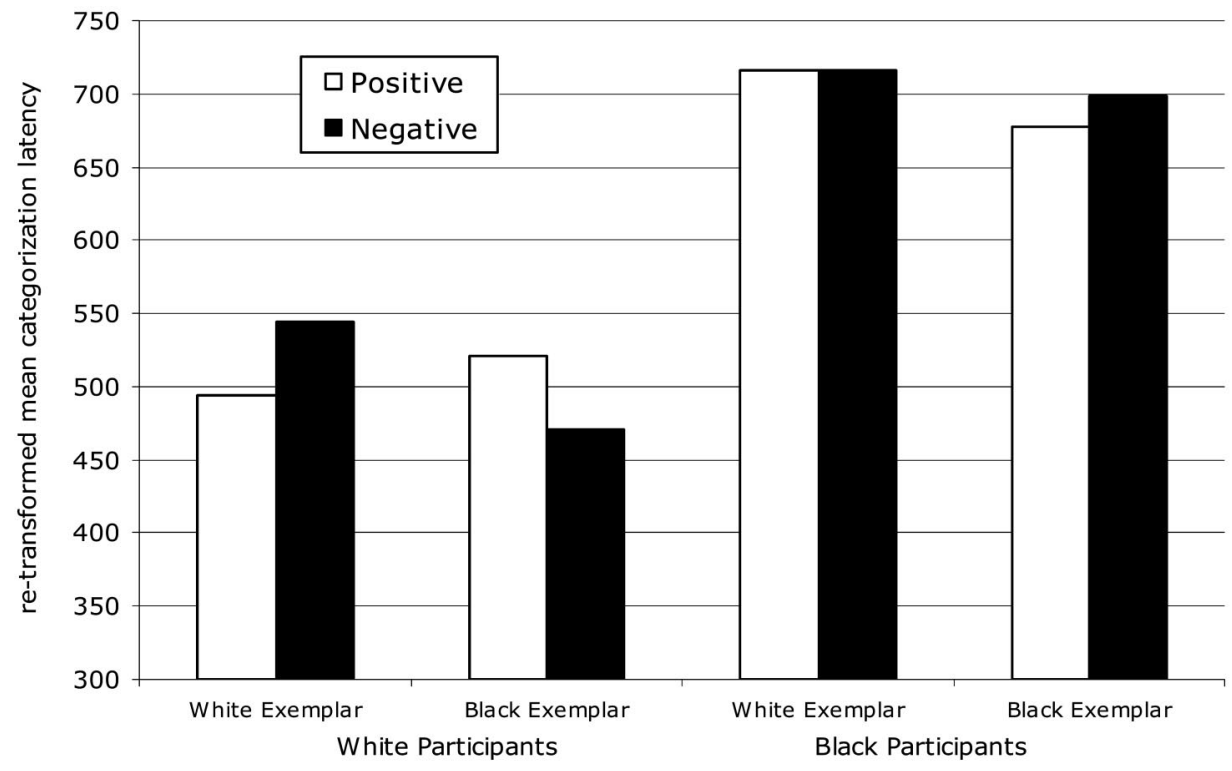

Figure 4. Study 4: Racial categorization latencies of unfamiliar, positive, and negative exemplars by Black and White participants.

Black exemplars, but faster to categorize liked White exemplars than disliked White exemplars. The main study tested this hypothesis.

\section{Participants and Design}

Fourteen White ( 9 female and 5 male) and 14 Black ( 8 female and 6 male) American students volunteered to participate in the experiment. The experiment was a 2 (participant race: White, Black) $\times 2$ (exemplar valence: positive or negative) $\times 2$ (exemplar race: White or Black) factorial design.

\section{Procedure}

The procedures were similar to those described in the previous studies; however, Study 4 consisted of only two phases: (a) training and (b) categorization. In Phase 1, 10 White and 10 Black male exemplars were presented in two counterbalanced blocks. Exemplars were selected from among a set of black-and-white yearbook photographs. The faces used were selected to be roughly equivalent in attractiveness, facial affect, and facial hair. Half of the exemplars of each race were introduced with the positive "charitable" information, and the other half were introduced with the negative "embezzler" information. The order of presentation of the set of positive (charitable) and negative (embezzler) exemplars was counterbalanced across participants, as was the set of photographs included in each set. Furthermore, the order of presentation of photographs in each block was randomized. Unlike in the previous studies, participants had no time limit on stimulus presentation during Phase 1 , and were instead asked to take their time and to form an impression of each exemplar. Participants were told that the faces would be "tagged" to help them remember the information they learned about each exemplar and were told which category each tag corresponded to; tags were counterbalanced across participants $(X, O=$ embezzler, charitable). The tags were counterbalanced across participants. In Phase 2, participants were presented with all the previously presented exemplars as well as 10 unfamiliar, filler exemplars that were not tagged, drawn from the same set of yearbook faces as the others. Participants then categorized the photographs by race, as quickly and accurately as possible, similar to the previous studies. Upon completion, participants were debriefed, thanked, and dismissed.

\section{Results and Discussion}

Data were trimmed and transformed in a manner identical to that reported for Study 1; however, trials greater than 2,000 ms were recoded as $2,000 \mathrm{~ms}$ in order to conform to the 3-standarddeviation-above-the-mean exclusion criterion (error trials $=$ $2.1 \%$ ). The data were then submitted to a 2 (participant race: White, Black) $\times 2$ (exemplar valence: positive or negative) $\times 2$ (exemplar race: Black or White) repeated measures ANOVA. The mean latencies are shown in Figure 4. The main effect of participant race was significant, revealing that Black participants took considerably longer to make their categorization judgments than White participants, $F(1,26)=15.6, p<.0005$. Furthermore, the expected three-way interaction between participant race, exemplar race, and exemplar valence was also reliable, $F(1,26)=4.42, p=$ .05. Separate analyses for each participant group revealed no evidence of differential categorization by the Black participants (all $F \mathrm{~s}<1$ ). Contrary to predictions, in other words, Black participants did not seem to be affected by the valence of the Black and White exemplars in any systematic manner. Perhaps the extremely long judgment latencies reflect increased deliberation by the Black participants in an attempt not to fall prey to the influence of stereotypes or otherwise irrelevant information. ${ }^{8}$

Analyses of the White participant sample revealed the now familiar interaction between exemplar race and type, $F(1,13)=$ 21.7, $p<.0005$. Consistent with predictions, White participants categorized positive White exemplars faster than negative White exemplars, $t(13)=2.76, p<.05$, but they categorized negative Black exemplars more quickly than positive Black exemplars,

\footnotetext{
${ }^{8}$ It is also important to note that only White participants were included in our pretesting, and, therefore, the results for the Black sample may also reflect these participants' differential perceptions of target stereotypicality and/or valence.
} 
$t(13)=2.61, p<.05$. Moreover, and consistent with the marked categorization advantage, White participants categorized disliked Black exemplars more quickly than disliked White exemplars, $t(13)=3.69, p<.005$. In contrast to marked categorization, however, White participants did not categorize positive Black exemplars any faster than admired White exemplars, $t(13)=0.96$, $p>.30 .^{9}$ Consistent with Study 1, therefore, these data suggest that the categorization advantage afforded to minority and otherwise nondominant classes of social categories (e.g., Blacks, women) does not withstand alterations of affective information that, we argue, is critical to the conceptualization of the group.

In sum, the findings for the White participants in the present study, coupled with the results of Studies 1 through 3, lend striking support to the premise that the affect associated with an exemplar can impact the facility with which he or she is categorized into positively valenced, compared with negatively valenced, racial categories. In other words, the affective fit between an exemplar and his or her social group wields an important influence on the facility with which that exemplar is correctly identified as a member of the particular social group.

\section{General Discussion}

The process of social categorization has been thought of as automatic, and inflexible, for certain categories (for instance, age, race, gender; e.g., Allport, 1954; Bargh, 1999; Devine, 1989; Fiske \& Neuberg, 1990; but see also Gilbert \& Hixon, 1991; Macrae \& Bodenhausen, 2000). That is, individuals tend to be categorized by gender and age, and often by race, relatively automatically by social perceivers. Deviating somewhat from this research, the present work examined whether affective information regarding group exemplars moderates the racial categorization process. Although racial category membership may seem to be solely dependent on seemingly diagnostic criteria, such as skin tone, the present results suggest that information regarding the likeability of an exemplar can also impact its category inclusion.

Studies 1 and 4 revealed, for instance, that White perceivers categorized admired (or liked) exemplars of disliked racial groups and disliked exemplars of admired racial groups more slowly than more affectively congruent exemplars. Specifically, we found that infamous and disliked Black exemplars were categorized more quickly than admired and liked Black exemplars. Conversely, admired and liked White exemplars were categorized more quickly than disliked White exemplars. Using an inverted-face paradigm, Study 2 revealed a similar pattern in the categorization errors made by White perceivers. Considered in the context of previous research on exemplar-category fit, the results of these studies suggest that there is a perceptual gap between both admired Black exemplars and disliked White exemplars and their respective racial groups, at least for White perceivers. Similar to people's sluggish categorization of ostriches as birds, in other words, White participants seem to be relatively sluggish to categorize admired Black exemplars and disliked White exemplars.

Moreover, Study 3 revealed that some White individuals may be relatively more likely to engage in such psychological distancing. Specifically, White participants who reported feeling particularly positively about their racial group membership were more likely to categorize disliked White exemplars more slowly than admired White exemplars and admired Black exemplars more slowly than disliked Black exemplars. Recent research examining the categorization of "ambiguously raced" (e.g., multiracial) individuals has shown that both group identification and prejudice are associated with being concerned about "contaminating" the in-group through the accidental inclusion of out-group members (Blascovich, Wyer, Swart, \& Kibler, 1997; Castano et al., 2002; Hugenberg \& Bodenhausen, 2004). Similar to this work, the participants with higher levels of PCSE in Study 3 may have been concerned, at least in part, about maximizing the positive distinctiveness of their racial group, relative to individuals with lower levels of PCSE. Future research is necessary, however, to make the claim that the results of the present work are due to motivated cognitive processes. Nevertheless, taken together, the results of the present work suggest that seemingly irrelevant information regarding exemplars of these basic categories (i.e., affective information) can wield substantial influence on social categorization processes.

\section{On Racial Categorization}

Clearly, the present findings offer a number of practical and theoretical implications. First, the sluggishness with which White perceivers racially categorize disliked White and admired Black exemplars suggests that such exemplars are less likely to influence judgments about their racial groups or to spontaneously be brought to mind when the category is activated (Rothbart \& John, 1985; Rothbart \& Lewis, 1988; Smith \& Zárate, 1992). On the whole that is, this work finds that judgments of groups are most often generated from typical exemplars rather than from atypical exemplars. The present research suggests that admired Blacks and disliked Whites are affectively atypical, and thus, they may be largely irrelevant to the impressions and evaluations formed of Blacks and Whites, respectively. Consistent with this sentiment, Dasgupta and Greenwald (2001) asserted that racial prejudice could be attenuated by reconnecting the races of disliked White exemplars and admired Black exemplars to their valences (Dasgupta \& Greenwald, 2001). The findings of the present research reveal the basic-level processes that make such a prescription both necessary and terribly arduous.

This issue of the "psychological status" of atypical group members has been investigated most thoroughly by research on subtyping - the phenomenon by which individuals who disconfirm group stereotypes are cordoned off from the group and discounted as group members (Kunda \& Oleson, 1995; Park, Wolsko, \& Judd, 2001; Weber \& Crocker, 1983). Given the aforementioned research revealing that atypical members of racial groups can and do influence attitudes about the group (Bodenhausen et al., 1995; Dasgupta \& Greenwald, 2001), it is unlikely that they are completely subtyped. Similar to this work, participants in our studies had little trouble categorizing the exemplars (i.e., during upright presentations), making very few errors. Perhaps, being completely

\footnotetext{
${ }^{9}$ It is important to note that the marked categorization advantage was not observed for the unfamiliar targets by either the White participant sample, $t(13)=0.24, n s$, or the Black participant sample, $t(13)=0.81, n s$. One possible explanation for this null result in the White sample is that ministers are perceived to be relatively positive, without explicit mention of any additional information. Consequently, unless information about specific negative behavior is made salient, then individual ministers will be perceived similar to other positive exemplars.
} 
separated or subtyped from a visible racial category is relatively rare and uncommon, especially in the United States, where the Black-White divide has particular historical significance (e.g., Devine \& Baker, 1991). Instead, previous research and our findings suggest that admired Black and disliked White exemplars are perceived as less consistent with the prototype of their respective racial categories and generally inconsistent with automatically activated feelings about their racial categories. In other words, these exemplars seem to maintain their membership in their racial groups yet, nevertheless, are held at some distance from the prototypes of their groups.

Moreover, the findings of Study 4 suggest that affective information, even in the absence of information about stereotypicality, can influence the racial categorization process. That is, thieving and charitable ministers were rated as being equally stereotypical of both Whites and Blacks; however, White perceivers categorized thieving (negative) Black ministers more quickly than charitable (positive) Black ministers, and they revealed the opposite pattern for thieving and charitable White ministers. These findings, in particular, suggest that traditional notions of subtyping, as well as models of exemplar-category fit, should be extended to consider the influence of affective information. The present work offers a first-step toward such an extension.

\section{On Face Processing}

The present work also has implications for models of face processing (Bruce \& Young, 1986). The model forwarded by Bruce and Young, for instance, argues that separate neural systems are involved in the identification and racial categorization of faces. That is, one stream underlies the recognition of the person, and the second allows for the extraction of information that is not necessary for person identification (although not completely unrelated to it). For instance, this second stream is thought to be concerned with mutable aspects of the face, such as facial expressions of emotion, as well as social category information, such as race, gender, and age. Recent research in both cognitive psychology and cognitive neuroscience is reconsidering the extent to which these two processing streams are indeed independent (Dubois et al., 1999; Hosie, Ellis, \& Haig, 1988; Young, Hay, McWeeny, Flude, \& Ellis, 1985). Consistent with this work, the present findings suggest the influence of identity information in the racial categorization process. That is, insofar as perceivers must recognize the familiar faces in order to access information about their likeability in Studies 1 to 3 for likeability to influence the rate at which they categorize the faces, then the stream through which identity is processed must communicate with the stream through which race is processed.

The interrelations among identity information and racial categorization in the present research are also striking given that the present results emerged for unambiguous exemplars of the relevant racial groups. Unlike other recent research examining influences on racial categorization when visual cues to racial group membership are either limited or ambiguous (e.g., Blascovich et al., 1997; Castano et al., 2002; Eberhardt, Dasgupta, \& Banaszynski, 2003; Hugenberg \& Bodenhausen, 2004), the racial group memberships of both the famous and the unfamiliar targets in the present work were readily identifiable based on visual cues. Nevertheless, we found differences in both categorization latency and accuracy as a function of exemplar likeability. Thus, the present findings extend this and other research examining racial categorization, suggesting that the fit between perceivers' affective orientations toward targets and their social categories influences the facility with which those targets are verified as category members.

\section{Practical Implications}

In addition to the theoretical implications reviewed previously, the present findings have implications for relations between members of dominant and minority racial groups. Behaving in counterstereotypical ways may be the only way for Blacks and Latinos to be successful and gain favor in schools and workplaces. However, the present work suggests that their identity as group members may be underplayed, if not ignored, in the minds of the White individuals with whom they interact. Indeed, this sentiment is consistent with Black women's accounts of their experiences in large corporations that document their feeling that the more successful they are, the less their peers acknowledge their racial group membership (Bell \& Nkomo, 2001). Thus, in some instances Blacks may be punished both for being "too Black," and for being "not Black enough." In addition, holding a color-blind approach to race relations may unwittingly play into this pattern of psychological distancing. That is, one can ignore the race of admired Blacks, but not of stereotypically disliked Blacks. This possibility is consistent with recent research finding that a color-blind perspective on race relations is associated with greater racial bias than a multicultural perspective in which racial group memberships are not ignored (Richeson \& Nussbaum, 2004). Thus, the psychological distancing of admired exemplars of stigmatized racial groups and disliked exemplars of dominant racial groups may be both a consequence of prejudiced attitudes and a barrier to diversification efforts aimed at prejudice reduction. In other words, the differential distancing of disliked White exemplars and admired Black exemplars from their racial categories may serve to maintain the relative status between the two racial groups.

\section{Conclusions}

In the last few decades a number of studies have been conducted examining factors that influence racial categorization. These studies find that both informational cues and perceptual cues can influence the facility with which individuals are verified as group members. For instance, previous research has shown that information suggesting that group members are relatively counterstereotypical of their groups slows the rate at which they were verified as group members (e.g., Smith \& Zárate, 1990, 1992; Zárate \& Smith, 1990). Similarly, recent research has shown that having physical features that are prototypical of the group facilitates categorization (Blair et al., 2002; Maddox \& Gray, 2003). The findings of the present research suggest a third factor that influences the speed with which exemplars are categorized as group members; namely, affective information about the exemplars. Specifically, the present research suggests that the fit or match between the valence of the exemplar and the valence of the group membership affects the racial categorization process. Admired exemplars of valued groups were categorized more quickly and more accurately than were disliked exemplars of valued groups, and disliked exemplars of devalued groups were categorized more 
quickly and accurately than admired exemplars of devalued groups. In other words, this work offers a new perspective on the categorization of exemplars into social categories, emphasizing affect, rather than characteristics, as typicality information.

\section{References}

Allport, G. W. (1954). The nature of prejudice. Reading, MA: Addison Wesley.

Bargh, J. A. (1999). The cognitive monster: The case against the controllability of automatic stereotype effects. In S. Chaiken \& Y. Trope (Eds.), Dual process theories in social psychology (pp. 361-382). New York: Guilford Press.

Bell, E. L. J., \& Nkomo, S. M. (2001). Our separate ways: Black and White women and the struggle for professional identity. Boston: Harvard Business School Press.

Blair, I. V., Judd, C. M., Sadler, M. A., \& Jenkins, C. (2002). The role of Afrocentric features in person perception: Judging by features and categories. Journal of Personality and Social Psychology, 83, 5-25.

Blascovich, J., Wyer, N. A., Swart, L. A., \& Kibler, J. L. (1997). Racism and racial categorization. Journal of Personality and Social Psychology, $72,1364-1372$.

Bodenhausen, G. V., Schwarz, N., Bless, H., \& Wänke, M. (1995). Effects of atypical exemplars on racial beliefs: Enlightened racism or generalized appraisals? Journal of Experimental Social Psychology, 31, 48-63.

Brewer, M. B., Dull, V., \& Lui, L. (1981). Perceptions of the elderly: Stereotypes as prototypes. Journal of Personality and Social Psychology, 41, 656-670.

Bruce, V., \& Young, A. W. (1986). Understanding face recognition. British Journal of Psychology, 77, 305-327.

Castano, E., Yzerbyt, V., Bourguignon, D., \& Seron, E. (2002). Who may enter? The impact of in-group identification on in-group/out-group categorization. Journal of Experimental Social Psychology, 38, 315-322.

Castelli, L., Zogmaister, C., Smith, E. R., \& Arcuri, L. (2004). On the automatic evaluation of social exemplars. Journal of Personality and Social Psychology, 86, 373-387.

Crocker, J., Luhtanen, R., Blaine, B., \& Broadnax, S. (1994). Collective self-esteem and psychological well-being among White, Black, and Asian college students. Personality and Social Psychology Bulletin, 20, 503-513.

Dasgupta, A. G., \& Greenwald, A. G. (2001). Exposure to admired group members reduces automatic intergroup bias. Journal of Personality and Social Psychology, 81, 800-814.

De Houwer, J., Crombez, G., Baeyens, F., \& Hermans, D. (2001). On the generality of the affective Simon effect. Cognition and Emotion, 15, 189-206.

De Houwer, J., \& Eelen, P. (1998). An affective variant of the Simon paradigm. Cognition and Emotion, 12, 45-61.

Devine, P. G. (1989). Stereotypes and prejudice: Their automatic and controlled components. Journal of Personality and Social Psychology, $56,5-18$.

Devine, P. G., \& Baker, S. M. (1991). Measurement of racial stereotype subtyping. Personality and Social Psychology Bulletin, 17, 44-50.

Doosje, B., \& Ellemers, N. (1997). Stereotyping under threat: The role of group identification. In R. Spears, P. J. Oakes, N. Ellemers, \& A. S. Haslam (Eds.), The social psychology of stereotyping and group life (pp. 257-272). Malden, MA: Blackwell.

Dubois, S., Rossion, B., Schiltz, J. M., Bodart, J. M., Michel, C., Bruyer, R., \& Crommelinck, M. (1999). Effect of familiarity on the processing of human faces. NeuroImage, 9, 278-289.

Eberhardt, J. L., Dasgupta, N., \& Banaszynski, T. L. (2003). Believing is seeing: The effects of racial labels and implicit beliefs on face perception. Personality and Social Psychology Bulletin, 29, 360-370.

Fazio, R. H. (1990). A practical guide to the use of response latency in social psychological research. In C. Hendrick \& M. S. Clark (Eds.), Research methods in personality and social psychology: Review of personality and social psychology (Vol. 11, pp. 74-97). Thousand Oaks, CA: Sage.

Fazio, R. H. (1995). Attitudes as object-evaluation associations: Determinants, consequences, and correlates of attitude accessibility. In R. E. Petty \& J. A. Krosnick (Eds.), Attitude strength: Antecedents and consequences (pp. 247-282). Hillsdale, NJ: Erlbaum.

Fazio, R. H. (2001). On the automatic activation of associated evaluations: An overview. Cognition and Emotion, 15, 115-141.

Fiske, S. T. (1998). Stereotyping, prejudice, and discrimination. In D. T. Gilbert \& S. T. Fiske (Eds.), The handbook of social psychology (Vol. 2, pp. 357-411). Boston: McGraw-Hill.

Fiske, S. T., \& Neuberg, S. L. (1990). A continuum model of impression formation from category based to individuating processes: Influences of information and motivation on attention and interpretation. In M. P. Zanna (Ed.), Advances in experimental social psychology (Vol. 3, pp. 1-74). San Diego, CA: Academic Press.

Gilbert, D. T., \& Hixon, J. G. (1991). The trouble of thinking: Activation and application of stereotypic beliefs. Journal of Personality and Social Psychology, 60, 509-517.

Govan, C., \& Williams, K. D. (2004). Changing the affective valence of the stimulus items influences the IAT by re-defining the category labels. Journal of Experimental Social Psychology, 40, 357-365.

Greenwald, A. G., McGhee, D. E., \& Schwartz, J. L. K. (1998). Measuring individual differences in implicit cognition: The implicit association task. Journal of Personality and Social Psychology, 74, 1464-1480.

Hosie, J. A., Ellis, H. D., \& Haig, N. D. (1988). The effect of feature displacement on the perception of well-known faces. Perception, 17, 461-474.

Hugenberg, K., \& Bodenhausen, G. V. (2004). Ambiguity in social categorization: The role of prejudice and facial affect in race categorization. Psychological Science, 15, 342-345.

Jolicoeur, P., Gluck, M. A., \& Kosslyn, S. M. (1984). Pictures and names: Making the connection. Cognitive Psychology, 16, 243-275.

Kunda, Z., \& Oleson, K. C. (1995). Maintaining stereotypes in the face of disconfirmation: Constructing groups for subtyping deviants. Journal of Personality and Social Psychology, 68, 565-579.

Leder, H., \& Bruce, V. (2000). When inverted faces are recognized: The role of configural information in face recognition. The Quarterly Journal of Experimental Psychology, 53A, 513-536.

Livingston, R. W., \& Brewer, M. B. (2002). What are we really priming? Cue-based versus category-based processing of facial stimuli. Journal of Personality and Social Psychology, 82, 5-18.

Luhtanen, R., \& Crocker, J. (1992). A collective self-esteem scale: Selfevaluation of one's social identity. Personality and Social Psychology Bulletin, 18, 302-318.

Macrae, C. N., \& Bodenhausen, G. V. (2000). Social cognition: Thinking categorically about others. Annual Review of Psychology, 51, 93-120.

Maddox, K. B., \& Gray, S. A. (2002). Cognitive representations of Black Americans: Reexploring the role of skin tone. Personality and Social Psychology Bulletin, 28, 250-259.

Marques, J. M., Robalo, E. M., \& Rocha, S. A. (1992). Ingroup bias and the "black sheep" effect: Assessing the impact of social identification and perceived variability on group judgments. European Journal of Social Psychology, 22, 331-352.

Marques, J. M., \& Yzerbyt, V. Y. (1988). The black sheep effect: Judgmental extremity towards ingroup members in inter- and intra-group situations. European Journal of Social Psychology, 18, 287-292.

Maurer, K. L., Park, B., \& Rothbart, M. (1995). Subtyping versus subgrouping processes in stereotype representation. Journal of Personality and Social Psychology, 69, 812-824.

Mitchell, J. P., Nosek, B. A., \& Banaji, M. R. (2003). Contextual variations 
in implicit evaluation. Journal of Experimental Psychology: General, 132, 455-469.

Nosek, B. A., Banaji, M. R., \& Greenwald, A. G. (2002). Harvesting implicit group attitudes and beliefs from a demonstration website. Group Dynamics, 6, 101-115.

Olson, K. R., Lambert, A. J., \& Zacks, J. M. (2004). Graded structure and the speed of category verification: On the moderating effects of anticipatory control for social vs. non-social categories. Journal of Experimental Social Psychology, 40, 239-246.

Park, B., Wolsko, C., \& Judd, C. M. (2001). Measurement of subtyping in stereotype change. Journal of Experimental Social Psychology, 37, 325-332.

Posner, M. I., \& Keele, S. W. (1968). On the genesis of abstract ideas. Journal of Experimental Psychology, 77, 353-363.

Ratcliff, R. (1993). Methods for dealing with reaction time outliers. Psychological Bulletin, 114, 510-532.

Richeson, J. A., \& Ambady, N. (2001). When roles reverse: Stigma, status, and self-evaluation. Journal of Applied Social Psychology, 31, 13501377.

Richeson, J. A., \& Ambady, N. (2003). Effects of situational power on automatic racial prejudice. Journal of Experimental Social Psychology, 39, 177-183.

Richeson, J. A., \& Nussbaum, R. J. (2004). The impact of multiculturalism versus color-blindness on racial bias. Journal of Experimental Social Psychology, 40, 417-423.

Rips, L. J., Shoben, E. J., \& Smith, E. E. (1973). Semantic distance and the verification of semantic relations. Journal of Verbal Learning and Verbal Behavior, 12, 1-20.

Rosch, E. (1978). Principles of categorization. In E. Rosch \& B. B. Lloyd (Eds.), Cognition and categorization (pp. 27-48). Hillsdale, NJ: Erlbaum.

Rosch, E., Mervis, C. B., Gray, W., Johnson, D., \& Boyes-Braem, P. (1976). Basic objects in natural categories. Cognitive Psychology, 8, 382-439.

Roskos-Ewoldsen, D. R., \& Fazio, R. H. (1992). On the orienting value of attitudes: Attitude accessibility as a determinant of an object's attraction of visual attention. Journal of Personality and Social Psychology, 63, $198-211$

Rothbart, M., \& John, O. P. (1985). Social categorization and behavioral episodes: A cognitive analysis of the effects of intergroup contact. Journal of Social Issues, 41(3), 81-104.

Rothbart, M., \& Lewis, S. (1988). Inferring category attributes from exemplar attributes: Geometric shapes and social categories. Journal of Personality and Social Psychology, 55, 861-872.

Rothbart, M., Sriram, N., \& Davis-Stitt, C. (1996). The retrieval of typical and atypical category members. Journal of Experimental Social Psychology, 32, 309-336.

Smith, E. R., \& Zárate, M. A. (1990). Exemplar and prototype use in social categorization. Social Cognition, 8, 243-262.

Smith, E. R., \& Zárate, M. A. (1992). Exemplar-based model of social judgment. Psychological Review, 99, 3-21.

Stroessner, S. J. (1996). Social categorization by race or sex: Effects of perceived non-normalcy on response times. Social Cognition, 14, 247276.

Tajfel, H., \& Turner, J. C. (1986). The social identity theory of intergroup behavior. In S. Worchel \& W. Austin (Eds.), The social psychology of intergroup relations (pp. 7-24), Chicago: Nelson-Hall.

Valentine, T. (1988). Upside-down faces: A review of the effect of inversion upon face recognition. British Journal of Psychology, 79, 471-491.

Weber, R., \& Crocker, J. (1983). Cognitive processes in the revision of stereotypic beliefs. Journal of Personality and Social Psychology, 45, 961-977.

Yin, R. K. (1969). Looking at upside-down faces. Journal of Experimental Psychology, 81, 141-145.

Young, A. W., Hay, D. C., McWeeny, K. H., Flude, B. M., \& Ellis, A. W. (1985). Matching familiar and unfamiliar faces on internal and external features. Perception, 14, 737-746.

Zárate, M. A., \& Sandoval, P. (1995). The effects of contextual cues on making occupational and gender categorizations. British Journal of Social Psychology, 34, 353-362.

Zárate, M. A., \& Smith, E. R. (1990). Person categorization and stereotyping. Social Cognition, 8, 161-185.

\section{Appendix}

Exemplars Used in Studies 1 Through 3

\begin{tabular}{llll}
\hline \multicolumn{1}{c}{ Admired Black } & \multicolumn{1}{c}{ Disliked Black } & Admired White & Disliked White \\
\hline Martin Luther King Jr. & O. J. Simpson & John F. Kennedy & Jeffrey Dahmer \\
Colin Powell & Mike Tyson & Lance Armstrong & Timothy McVeigh \\
Denzel Washington & Snoop Doggy Dogg & Rudy Giuliani & Howard Stern \\
Muhammad Ali & Malcolm X & Cal Ripkin, Jr. & Eminem \\
Bill Cosby & Darryl Strawberry & John Lennon & Adolf Hitler \\
Barry Bonds & Jesse Jackson & Mark McGuire & Gary Condit \\
Wil Smith & Sean "P. Diddy"Combs & George Clooney & Pete Rose \\
\hline
\end{tabular}

Received November 7, 2003

Revision received May 4, 2005

Accepted May 13, 2005 